\title{
Universals and specifics of the structure and hierarchy of basic human values in Vietnam
}

\begin{abstract}
BACKGROUND
The article presents the first assessment of the structure and hierarchy of values using the Schwartz theory in Vietnam. Given the near-universal prevalence of the structure of values, we expected this to be found in Vietnam as well. Regarding the hierarchy of values, we expected the hierarchies in the Vietnamese samples to be quite different from the pan-cultural baseline because of Vietnam's traditional culture.
\end{abstract}

\section{PARTICIPANTS AND PROCEDURE}

We administered a Vietnamese version of the Portrait Value Questionnaire (PVQ-40) to adult respondents in three regions, Ho Chi Minh City/Saigon $(n=521)$, Hue $(n=538)$, and Hanoi $(n=533)$.

\section{RESULTS}

Multidimensional scaling (MDS) and confirmatory factor analysis (CFA) analyses of the total sample and the sam- ples from each region supported the theorized circular structure. However, it was necessary to combine some adjacent values in the circle in each sample. The hierarchies of values in the samples differed substantially from the pan-cultural hierarchy identified by Schwartz and Bardi. The values exhibited partial scalar invariance across the three regional samples, justifying comparisons of means.

\section{CONCLUSIONS}

We discuss the differences in value hierarchies among regions and between Vietnam and other countries by examining the cultural, historical, and social structural characteristics specific to Vietnam and its regions. In future research, it would be worthwhile to explore causes, processes and consequences of the values in Vietnam.

\section{KEY WORDS}

Vietnam; structure of values; human values; hierarchy of values; PVQ-40

ORganization - 1: Institute of Psychology, University of Gdansk, Gdansk, Poland · 2: University of Social Sciences and Humanities in Hanoi, Vietnam · 3: Institute of Psychology, University of Cardinal Stefan Wyszynski in Warsaw, Poland · 4: University Research Priority Program Social Networks, University of Zürich, Switzerland · 5: The Hebrew University of Jerusalem, Israel · 6: National Research University-Higher School of Economics, Moscow, Russia AUthors' CONTRibutions - A: Study design - B: Data collection - C: Statistical analysis - D: Data interpretation . E: Manuscript preparation · F: Literature search · G: Funds collection CORRESPONDING AUthor - Joanna Różycka-Tran, Ph.D., Institute of Psychology, University of Gdansk, 4 Bażyńskiego Str., 80-309 Gdansk, Poland, e-mail: psyjrt@ug.edu.pl 


\section{BASIC HUMAN VALUES}

The identification and exploration of universal dimensions of human cultures are a central concern of cross-cultural psychology. This etic approach (see Bond et al., 2004) is exemplified by the varied studies seeking to identify dimensions for characterizing diverse world cultures based on individual or cultural values (Hofstede, 1991; House, Hanges, Javidan, Dorfman, \& Gupta, 2004; Inglehart, 1997; Schwartz, Joanna 1992, 2004, 2012). The concept of values has a long Różycka-Tran, Truong Thi Khanh $\mathrm{Ha}$, Jan Cieciuch, Shalom $\mathrm{H}$. Schwartz and diverse history in psychology and other social sciences (Hitlin \& Piliavin, 2004; Rohan, 2000). Nonetheless, Schwartz (1992) was able to identify many points of convergence in the different conceptions of human values. He then developed his model of the content and structure of values (Schwartz, 1992; Schwartz et al., 2012) that is widely used in research on values. The current paper applies this model for the first time to samples from Vietnam.

Building on the work of Rokeach (1973), Schwartz (1992) defined values as trans-situational goals, varying in importance, that serve as guiding principles in people's lives. Schwartz summarized the following five formal features that recur in most definitions of values: Values (a) are concepts or beliefs, (b) pertain to desirable end states or behaviors, (c) transcend specific situations, (d) guide the selection or evaluation of behavior and events, and (e) are ordered by relative importance (Schwartz, 1992, 2006). Values represent, in the form of conscious goals, three universal requirements of human existence: biological needs, requisites of coordinated social interaction, and demands of group survival and functioning (Schwartz, 1992; Schwartz \& Bilsky, 1987). Groups and individuals cognitively represent these requirements as specific values about which they communicate to explain, coordinate, and rationalize behavior (Schwartz \& Bardi, 2001).

The core of Schwartz's theory is the identification of values according to the motivation that underlies them. This enabled him to specify how different values form a circular structure that captures the conflicts and compatibility among the motivations they express. Research in over 80 cultural groups has validated the motivationally distinct content of the 10 values in the theory and the relations of conflict and compatibility among them (e.g., Bilsky, Janik, \& Schwartz, 2011; Schwartz, 1992, 2006).

In the classic version of his theory, Schwartz (1992) partitioned the circle into 10 basic human values, each defined in terms of its central motivational goal: (1) Universalism: Understanding and protection for the welfare of all people and for nature; (2) Benevolence: Caring for the welfare of the people with whom one is in frequent personal contact; (3) Tradition: Respect and acceptance of the customs and ideas that one's culture or religion provide; (4) Conformity: Restraint of actions and impulses likely to upset or harm others and violate social expectations or norms; (5) Security: Safety, harmony, and stability of society, of relationships, and of self; (6) Power: Social status and prestige, control and dominance over people and resources; (7) Achievement: Personal success through demonstrating competence in accordance with social standards; (8) Hedonism: Pleasure, gratification of the senses; (9) Stimulation: Excitement, novelty, and challenge in life; (10) Self-direction: Independent thought and action - choosing, creating, exploring (Schwartz, 1992). These values can be grouped into four higher order values that form two bipolar dimensions. The first dimension contrasts self-transcendence values (universalism and benevolence) with self-enhancement values (power and achievement). The second dimension contrasts openness to change values (stimulation and self-direction) with conservation values (tradition, conformity, and security). Hedonism is located between openness to change and self-enhancement.

Of the numerous methods available to measure the 10 basic values, we employed the 40 -item Portrait Values Questionnaire (PVQ-40; Schwartz, 2006; Schwartz, Melech, Lehmann, Burgess, \& Harris, 2001). This instrument has been used in many studies that applied multidimensional scaling (MDS) or confirmatory factor analysis (CFA) and typically demonstrated that the 10 values can be differentiated and that they are ordered according to the theorized motivational circle, with only one exception: reversal of universalism and benevolence (e.g., Cieciuch \& Schwartz, 2012; Koivula \& Verkasalo, 2006; Liem, Martin, Nair, Bernardo, \& Hidajat, 2011; Schmidt, Bamberg, Davidov, Herrmann, \& Schwartz, 2007; Schwartz, 2006; Vecchione, Casconi, \& Barbaranelli, 2009).

\section{SIMILARITIES AND DIFFERENCES IN THE HIERARCHIES OF VALUES}

The Schwartz (1992) value theory distinguishes between value structures and value hierarchies. The circular motivational continuum refers to the value structure, which is near universal. Value hierarchies refer to the relative importance of the set of values. Value hierarchies vary between individuals within and across age, occupational, gender, national, ethnic, and other groups. Many studies have documented cultural differences in the importance of specific values (e.g., Hofstede, 1991; Inglehart, 1997; Markus \& Kitayama, 1991). These studies have assessed only two to four values at a time, however, rather than larger sets of values like the ten in the Schwartz (1992, 2006) theory. Consequently, they have not considered the extent to which elaborate value hierarchies may differ across cultural groups. 
A study by Schwartz and Bardi (2001) addressed this question. They examined the value hierarchies of samples from 60 countries from Asia, Africa, Latin America, the Middle East, East Europe, and West Europe. There were samples of teachers from 56 countries, students from 54, and representative samples from 13 . They found substantial similarity in the average value hierarchies across the different samples and countries. Specifically, benevolence was usually the most important value, followed by self-direction $\left(2^{\text {nd }}\right)$, universalism $\left(3^{\text {rd }}\right)$, security $\left(4^{\text {th }}\right)$, and conformity $\left(5^{\text {th }}\right)$. The five less important value were, in order, achievement, hedonism, stimulation, tradition, and power. Value hierarchies of $83 \%$ of samples correlated at least .80 with this pan-cultural hierarchy.

Samples from one set of countries differed substantially from the pan-cultural hierarchy of values. The hierarchies of the samples from the five sub-Saharan African countries were considerably less similar to the pan-cultural average than samples from other world regions. In these samples, conformity values were most important and appreciably more important than self-direction values. Schwartz and Bardi (2001) attributed the sub-Saharan pattern to the consequences of the region's particularly large, hierarchically organized families. More generally, they argued that it is the social structural characteristics shared by most but not all contemporary nations that give rise to the pan-cultural value hierarchy.

We discuss the relevant social structural characteristics in Vietnam below. We also note that these characteristics vary somewhat across regions of Vietnam. This makes it interesting to assess how the value hierarchies may differ across Vietnamese regions and to seek explanations for such differences. We also compare the hierarchies in Vietnamese samples with findings from around the world.

\section{THE CULTURE IN VIETNAM}

Vietnam is a typical collectivistic country (Hofstede, 1991), where social interactions and networks of mutual obligation are crucial for social functioning. According to the ecocultural model of human development, the tropical climate (with hot and rainy seasons) favors agriculture and hunting (Berry, 2004). Vietnam has been through three wars of national liberation in the past 65 year, for independence in 1945 , for the liberation of the north in 1954, and for the liberation of the south in 1975. These wars have undoubtedly also affected its culture. The renovation and cultural reconstruction of Vietnam that began in 1986 has seen a shift from a bureaucratic subsidy-based economy to a socialism-oriented market economy (Pham Minh Hac, 1998).
Vietnamese identity has been formed over thousands of years, resulting in numerous arguments regarding its characteristics. Dao Duy Anh (2000) distinguished five remarkable characteristics of Vietnamese people: (a) they tend to depend on intuition rather than science; (b) they are laborious and long-suffering; (c) if necessary, they can always sacrifice themselves for the greater good; (d) they are not very creative and prefer imitating others; (e) and they honor traditional customs (Dao Duy Anh, 2000). Tran Van Giau (1980) wrote that the Vietnamese mentality covers the following seven values: patriotism, diligence, heroism, creativity, optimism, charity, and benevolence. According to Tran Dinh Huou (1994), Vietnamese people: (a) are neither deeply religious nor interested in philosophical discussion; (b) they tend to be concerned with and care about their children rather than themselves; (c) they don't honor the idea of individualism and self-reliance; (d) their conception of happiness is generally simple, practical and not unattainable; (e) they respect good-natured and grateful people more than intelligent ones (Tran Dinh Huou, 1994).

Le Thi Lan (2009) claimed that the Vietnamese have preserved and developed a unique culture through the vitality of a tradition of reconciliation. Reconciliation is a primary living principle for Vietnamese that includes three aspects: (a) harmony with nature, such that people's actions are in accordance with nature rather than resisting nature, (b) harmony in social relations and communication through the principles of respecting peace and reconciling interests, and (c) harmony between and within culture and religion, as they received different foreign cultural elite factors such as Confucianism, Taoism, Buddhism, native religion, etc. (Le Thi Lan, 2009).

All the characteristics mentioned above are consistent with some studies (e.g. Truong, Nguyen, \& Różycka-Tran, 2015). The results of the World Values Survey, conducted with more than 1,000 people throughout the country, showed that most Vietnamese value peace, solidarity, cooperation, and mutual respect highly and also value patriotism and familial values (WVS, 1999-2004). In a survey carried out in 2014 in Vietnam, 5604 respondents from the north, middle and south of Vietnam, aged 15 to 74, were asked to select the seven most important values from a list of 21 . The four most frequently selected values were (a) happiness in family life $(82.93 \%)$, (b) stable employment $(75.47 \%)$, (c) justice in society $(53.42 \%)$, and (d) wealth (52.21\%) (Tran Ngoc Them, 2015).

Within Vietnam, there are regional differences in the extent of urbanization, political history, and current social functions. Moreover, dissimilar populations and climates in various regions (Pham Minh Hac, 1998) lead to cultural differentiation in other dimensions. This makes it worthwhile to study and compare values in northern, central, and southern parts of Vietnam.
Basic human values in Vietnam 


\section{THE CURRENT STUDY}

The current study provides the first examination of the distinctiveness, circular structure, and hierarchies of values in Vietnam. Given the near-universal prevalence of the structure of values, we expected this to be found in Vietnam as well. Specifically, we hypothesized that the PVQ-40 items form a circular, two-dimensional MDS structure that can be partitioned into 10 distinct values. Moreover, the 10 values can be combined into the four higher order values.

Regarding the hierarchy of values, we expected the hierarchies in the Vietnamese samples to be quite different from the pan-cultural baseline because of Vietnam's traditional and rural culture. Although the average family is not as large as in sub-Saharan African samples (the Vietnamese government allows having only two children), the ancestor worship and multigenerational tradition (three or four generations live together in one house) make it critical to organize families hierarchically and to expect members to conform to relatively strict norms in order for families to function smoothly. We hypothesized that, in contrast to the pan-cultural hierarchy of values (but similar to African samples), people in Vietnam would value conformity more than self-direction.

Because of the regional differences in social structure and history discussed above, we also expected some differences in the value hierarchies of the three representative regions: Hanoi, Hue and Ho Chi Minh City (Saigon). Hanoi is situated in the northern region of Vietnam; since 1975, it has been the capital and under a communist regime. Hue is situated in the central region, with the historical heritage of serving as the capital of the last feudal dynasty in Vietnam for more than 140 years (1802-1945). Ho Chi Minh City (Saigon) is located in the southern region; it is the largest and most populous metropolitan area in the country and is economically oriented. Saigon and Hanoi are the most Westernized (urbanized) of the cities, so their value hierarchy is most likely to resemble the pan-cultural hierarchy (Schwartz \& Bardi, 2001). We therefore hypothesized that benevolence and self-direction are more important in Hanoi, while power, achievement and stimulation are more important in Saigon, the economic capital of Vietnam - as power and achievement values have been found to be associated with competitive economic markets (Sagiv \& Schwartz, 2007).

\section{PARTICIPANTS AND PROCEDURE}

Data were gathered from parents of students at average-ranking high schools from three different (urban and rural) regions: north, central and south
Vietnam (Hanoi, Hue and Ho Chi Minh City respectively). We deleted data of respondents who gave the same answer to more than $70 \%$ of the items and those with more than $30 \%$ missing data (208 observations were excluded). After the data cleaning, the sample consisted of $n=1592$ respondents $(49 \%$ men), aged 36-76 $(M=45.72, S D=5.81)$. The adult respondents varied in age and educational level (primary, secondary, intermediate or graduate) and occupational backgrounds (e.g. officials, engineers, teachers, doctors and nurses, army and police staff, service workers, housewives, retired people, farmers and other workers).

The PVQ-40 questionnaire was administered in a paper-and-pencil format. Adults completed the questionnaire during parental meetings, which are held twice a semester in all schools. The survey was administered by university students under the supervision of researchers specializing in psychology after obtaining permission from teachers in participating institutions. The whole procedure took about 20 minutes. First, researchers explained the aim of the survey, then participants were invited to complete the questionnaire; the researchers were available to answer any questions whilst they were doing so. Participation was anonymous and voluntary.

\section{MEASURE}

The Portrait Values Questionnaire (Schwartz et al., 2001) consists of 40 items that are presented in the form of short verbal portraits that describe 40 different people. Each portrait describes a person's goals, aspirations, or desires, which point implicitly to the importance of a value. For example: "She/he thinks it is important that everybody in the world should be treated equally. She/he believes that everyone should have equal opportunities in life" (universalism); "She/he seeks every opportunity to have fun. It is important to her/him to do the things that give her/ him pleasure" (hedonism); "It is important to her/him to be rich. She/he wants to have a lot of money and expensive things" (power).

For each portrait, the respondents answer the question "How much like you is this person?" on a scale from 1 (not like me at all) to 6 (very much like me). The number of portraits for each value reflects the conceptual breadth of the basic values: three for stimulation, hedonism, and power, four for conformity, tradition, benevolence, self-direction, and achievement, five for security and six for universalism.

The Vietnamese version of the PVQ-40 was used in the current study. Following several iterations of translation, back-translation, and modification, the author of the PVQ-40 approved the translation (Różycka-Tran, Żemojtel-Piotrowska, \& Truong, 2013). 


\section{RESULTS}

\section{STRUCTURE OF VALUES IN VIETNAM}

After preliminary analysis, we dropped six items from further analysis because their locations in the MDS suggested that they were understood differently than intended. There was one deleted item from each of six values: conformity (item \#7), tradition (\#9), hedonism (\#10), benevolence (\#27), achievement (\#32), and self-direction (\#34).
We performed a theory-based MDS (Bilsky et al., 2011) on the remaining 34 items for the whole sample $(n=1592$, Stress- $1=.19)$ and separately for the samples from Hanoi $(n=533$, Stress- $1=.20)$, Hue $(n=538$, Stress- $1=.20)$, and Ho Chi Minh City $(n=521$, Stress- $1=.18)$. The stress-1 indexes indicate how well the two-dimensional MDS projections that were obtained represent the underlying covariance matrix. All were less than .20. For a matrix of 34 items, this value constitutes good representation (see Figures 1-4).
Basic human values in Vietnam

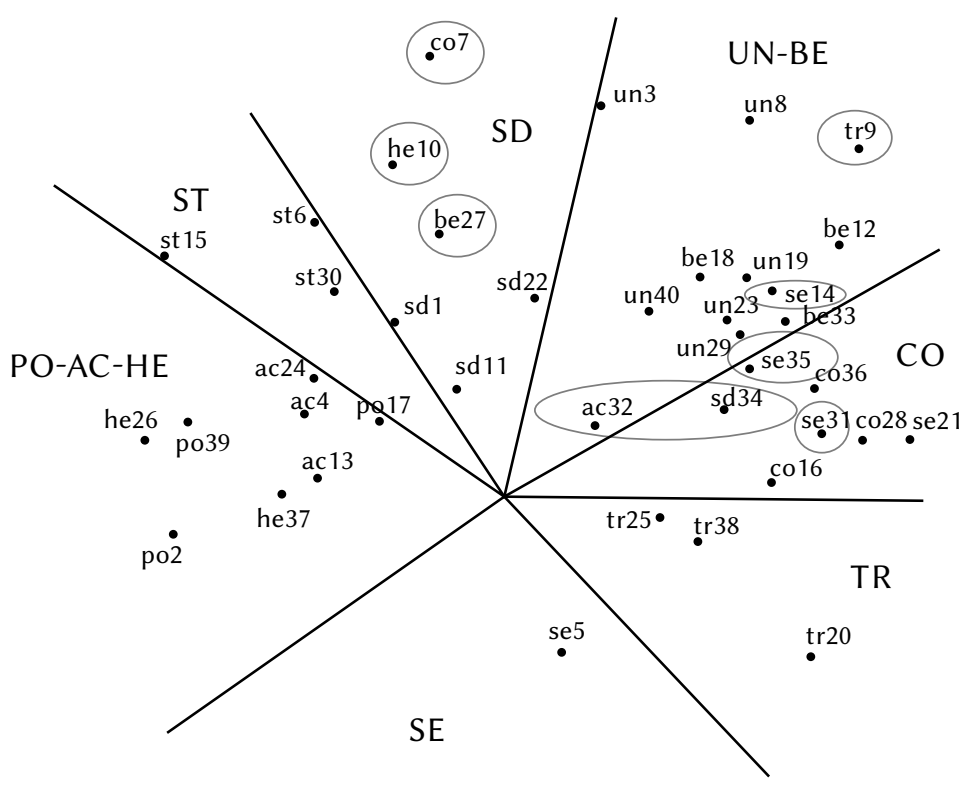

Note. SD - self-direction; UN - universality; BE - benevolence; TR - tradition; CO - conformity; SE - security; HE - hedonism; PO - power; AC - achievement; ST - stimulation; items (with name of values and number in PVQ) in gray circles are misallocated.

Figure 1. Theory-based multidimensional scaling on the whole sample $(n=1592$, Stress- $1=.19)$.

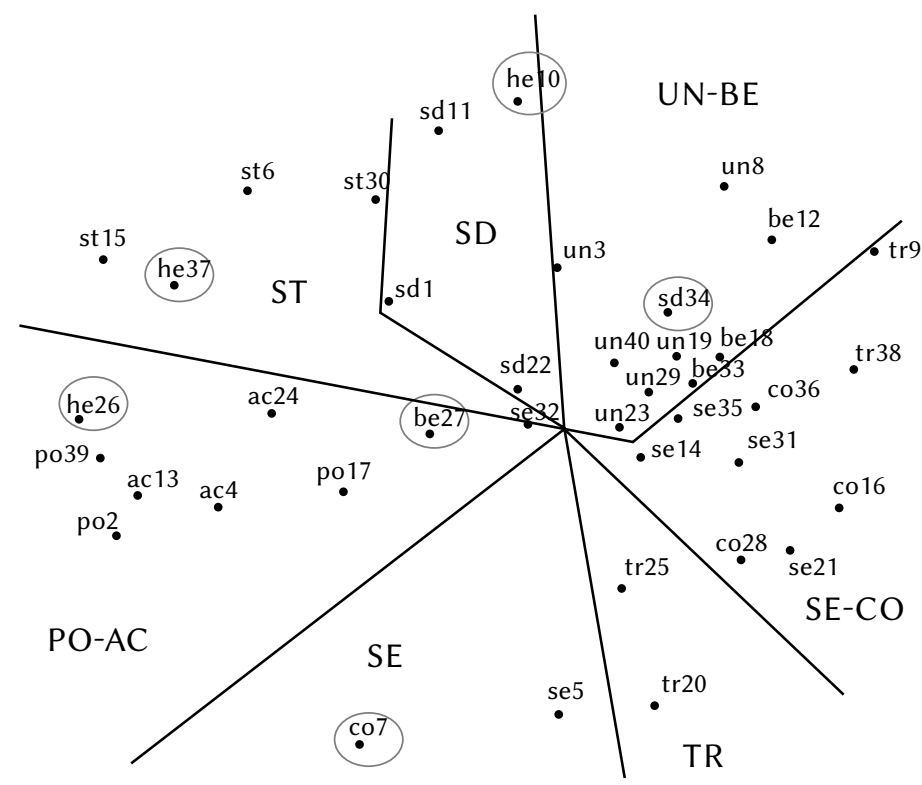

Note. SD - self-direction; UN - universality; BE - benevolence; TR - tradition; CO - conformity; SE - security; HE - hedonism; PO - power; AC - achievement; ST - stimulation; items (with name of values and number in PVQ) in gray circles are misallocated.

Figure 2. Theory-based multidimensional scaling on the Hanoi sample (40 items, $n=533$, Stress- $1=.22$ ). 
Joanna

Różycka-Tran, Truong Thi Khanh $\mathrm{Ha}$, Jan Cieciuch, Shalom H. Schwartz

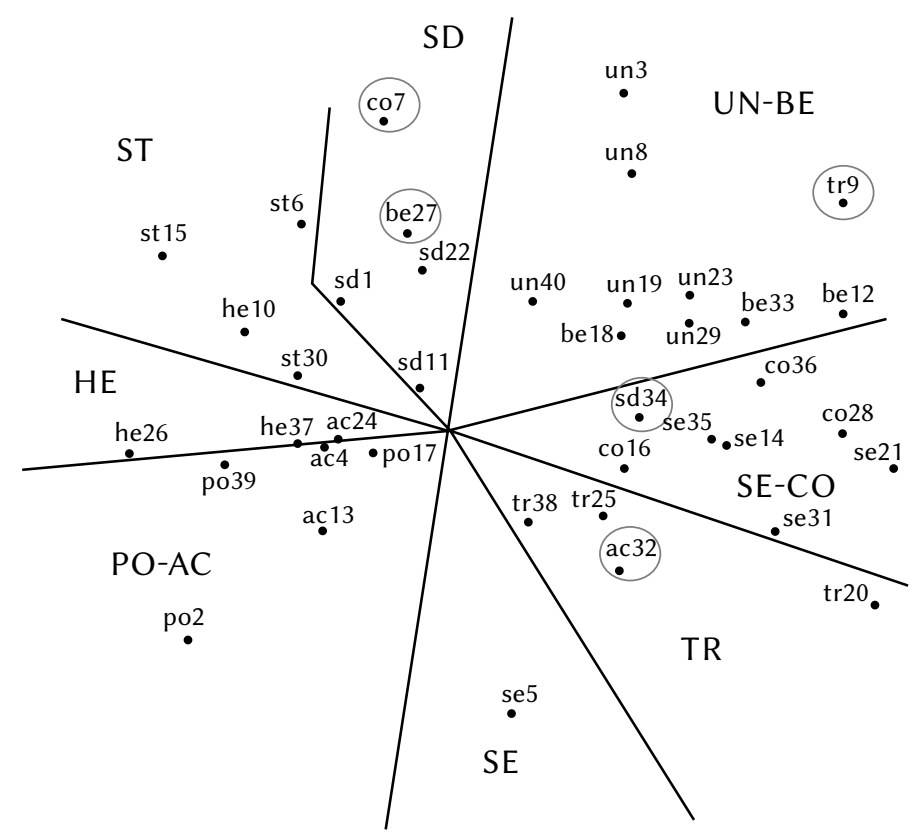

Note. SD - self-direction; UN - universality; BE - benevolence; TR - tradition; CO - conformity; SE - security; HE - hedonism; PO - power; AC - achievement; ST - stimulation; items (with name of values and number in PVQ) in gray circles are misallocated.

Figure 3. Theory-based multidimensional scaling on the Hue sample (40 items, $n=538$, Stress- $1=.22$ ).

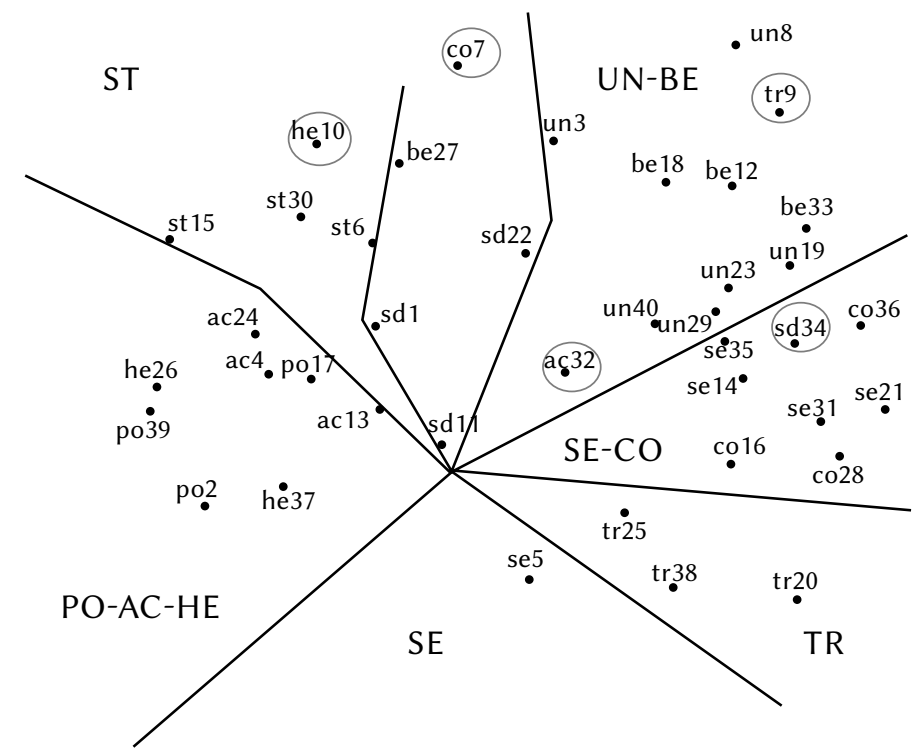

Note. SD - self-direction; UN - universality; BE - benevolence; TR - tradition; CO - conformity; SE - security; HE - hedonism; PO - power; AC - achievement; ST - stimulation; items (with name of values and number in PVQ) in gray circles are misallocated.

Figure 4. Theory-based multidimensional scaling on the Saigon sample (40 items, $n=521$, Stress-1 $=.20$ ).

The results confirmed the near-universal structure of the motivational circle. Although it was not possible to partition the MDS projection into distinct regions (sectors) of all 10 original values in the total sample MDS or any of the separate samples, the values that were intermixed were values that are adjacent in the theorized motivational circle. In the total sample, two combinations of adjacent values were necessary: power with achievement and hedonism, and universalism with benevolence. In the Hanoi sample, three combinations of adjacent values were necessary: power with achievement, security with conformity, and universalism with benevolence. In the Hue sample, one combination was needed: power with achievement. In the Saigon sample, three combinations were needed: power with achievement and hedonism, security with conformity, and universalism with benevolence.

Because all of the combined values are neighbors on the circle, the sequential order of the 10 values around the circle was supported. Moreover, values that express conflicting motivations were opposed in the circle. Of the 34 items, at least 30 emerged in 
their intended region in each sample. This degree of deviation by items from their intended region is typical of the findings in past MDS research with the PVQ-40 (Schwartz, 2006). We therefore conclude that the results support the circular structure of values in the overall Vietnamese sample and in each city.

The MDS provides a visual assessment of the distinctiveness of the different values. We used CFA to test their distinctiveness formally with Mplus 7.1 (Muthén \& Muthén, 1998-2012). We followed the approach, proposed by Cieciuch and Schwartz (2012), and generated a separate model for each of the four higher order categories of values (i.e., self-enhancement, self-transcendence, openness, and conservation according to theory). Thus, CFA was performed separately for each higher order value in each city (see Table 1).

To assess the goodness of fit of the models, we employed global fit indexes: the comparative fit index (CFI) comparing the fit of a model to a more restricted baseline model (Hu \& Bentler, 1999); the root mean square error of approximation (RMSEA) reflecting the degree to which a model fits the population covariance matrix (Brown, 2006; Browne \& Cudeck, 1993; $\mathrm{Hu} \&$ Bentler, 1999); and the standardized root mean square residual (SRMR) comparing the sample variances and covariances to the estimated variances and covariances (Hu \& Bentler, 1999).
It was necessary to unify some values because they were too highly correlated. This was the case for power and achievement in self-enhancement values and conformity, security and tradition in conservation values. As can be observed in Table 1, after this unification, all models (each higher order value in each city) fit the data well. RMSEA and SRMR are smaller than .08, and CFI is greater than .90. Factor loadings are substantial, and values load on higher order values, in line with the theory.

In further analyses we use seven values based on the results obtained in MDS and CFA: security-conformity-tradition, benevolence, universalism, self-direction, stimulation, hedonism, and achievement-power.

\section{COMPARABILITY OF VALUES ACROSS THREE REGIONS IN VIETNAM}

To test whether the values were understood and measured in the same way across the three regions of Vietnam, we tested for measurement invariance using multi-group confirmatory factor analysis (MGCFA; Bollen, 1989; Jöreskog, 1971) for each higher order value model. We tested three levels of measurement invariance: configural, metric and scalar (Davidov, Meuleman, Cieciuch, Schmidt, \& Billiet,

Table 1

Confirmatory factor analyses for higher order values

\begin{tabular}{|c|c|c|c|c|}
\hline & $\chi^{2}$ & CFI & RMSEA & SRMR \\
\hline \multicolumn{5}{|l|}{ Self-transcendence $(\mathrm{BE}, \mathrm{UN})^{1} d f=26$} \\
\hline Hanoi $(n=539)$ & 57.32 & .973 & $.047[.031-.064]$ & .033 \\
\hline Hue $(n=540)$ & 58.57 & .969 & $.048[.032-.065]$ & .033 \\
\hline Saigon $(n=533)$ & 68.63 & .960 & $.055[.040-.072]$ & .036 \\
\hline \multicolumn{5}{|l|}{ Self-enhancement (HE, PO-AC) $)^{2} d f=19$} \\
\hline Hanoi & 71.07 & .957 & $.071[.054-.089]$ & .037 \\
\hline Hue & 53.82 & .972 & $.058[.040-.077]$ & .032 \\
\hline Saigon & 78.24 & .952 & $.076[.059-.094]$ & .038 \\
\hline \multicolumn{5}{|l|}{ Openness $(\mathrm{ST}, \mathrm{SD})^{3} d f=8$} \\
\hline Hanoi & 14.85 & .984 & $.040[.000-.071]$ & .023 \\
\hline Hue & 22.06 & .968 & $.057[.029-.086]$ & .028 \\
\hline Saigon (one latent variable ST-SD) & 21.54 & .973 & $.051[.023-.079]$ & .027 \\
\hline \multicolumn{5}{|l|}{ Conservation (TR-CO-SE) ${ }^{4} d f=62$} \\
\hline Hanoi & 165.33 & .917 & $.056[.045-.066]$ & .042 \\
\hline Hue & 170.83 & .908 & $.057[.047-.067]$ & .043 \\
\hline Saigon & 157.07 & .927 & $.054[.043-.064]$ & .041 \\
\hline
\end{tabular}

Note. ${ }^{1}$ Benevolence loaded by the items: pvq12 pvq18 pvq33; Universalism: pvq19 pvq40 pvq3 pvq8 pvq23 pvq29; ${ }^{2} \mathrm{Hedonism}$ loaded by the items: pvq26 pvq37; Power-achievement: pvq4 pvq13 pvq24 pvq2 pvq17 pvq39; ${ }^{3}$ Stimulation loaded by the items: pvq6 pvq15 pvq30; Self-direction: pvq11 pvq1 pvq22; ${ }^{4}$ Tradition loaded by the items: pvq20 pvq25 pvq38; Conformity: pvq16 pvq36 pvq28; Security: pvq21 pvq31 pvq14 pvq35 pvq5; correlated uniqueness: pvq14 with pvq35; pvq21 with pvq20; pvq14 with pvq16. 
Table 2

Measurement invariance across three regions

\begin{tabular}{|c|c|c|c|c|c|}
\hline & $\chi^{2}$ & $d f$ & $\mathrm{CFI}$ & RMSEA & SRMR \\
\hline \multicolumn{6}{|c|}{ Self-transcendence (UN, BE) } \\
\hline Configural & 163.16 & 78 & .947 & $.064[.050-.078]$ & .043 \\
\hline Metric & 171.04 & 92 & .951 & $.057[.043-.070]$ & .051 \\
\hline Scalar & 227.01 & 106 & .925 & $.066[.054-.077]$ & .062 \\
\hline \multicolumn{6}{|c|}{ Self-enhancement (PO-AC, HE) } \\
\hline Configural & 131.82 & 57 & .958 & $.070[.055-.086]$ & .041 \\
\hline Metric & 146.13 & 69 & .957 & $.065[.050-.080]$ & .052 \\
\hline Scalar & 196.66 & 81 & .935 & $.073[.060-.086]$ & .064 \\
\hline \multicolumn{6}{|c|}{ Openness (SD, ST) } \\
\hline Configural & 57.91 & 24 & .943 & $.073[.049-.097]$ & .039 \\
\hline Metric & 67.37 & 32 & .941 & $.064[.043-.086]$ & .050 \\
\hline Scalar & 75.38 & 40 & .941 & $.058[.037-.078]$ & .053 \\
\hline \multicolumn{6}{|c|}{ Conservation (TR-CO-SE) } \\
\hline Configural & 360.93 & 186 & .903 & $.060[.050-.069]$ & .053 \\
\hline Metric & 380.67 & 210 & .906 & $.055[.046-.064]$ & .063 \\
\hline Scalar & 434.85 & 234 & .889 & $.057[.048-.065]$ & .069 \\
\hline
\end{tabular}

Note. $d f$ - degrees of freedom; CFI - comparative fit index; RMSEA - root mean square error of approximation; SRMR - standardized root mean square residual.

2014). To establish measurement invariance, we relied on the cutoff criteria suggested by Chen (2007). The results are presented in Table 2 .

We concluded that all higher order values demonstrated full configural invariance (all groups had the same pattern of factor loadings in each region). The metric invariance of all values was also supported across the three regions (all loadings were constrained to be equal across the three regions, indicating that the values were understood by respondents in the same

Table 3

The hierarchy and mean ratings of values in Vietnam $(n=1592)$

\begin{tabular}{lc}
\hline Scale & $\begin{array}{c}\text { Mean rating } \\
(S D)\end{array}$ \\
\hline Security-Conformity-Tradition & $4.33(0.65)$ \\
Benevolence & $4.23(0.78)$ \\
Universalism & $4.20(0.80)$ \\
Self-direction & $3.96(0.80)$ \\
Hedonism & $3.49(0.98)$ \\
Power-Achievement & $3.48(0.87)$ \\
Stimulation & $3.22(0.97)$ \\
\hline
\end{tabular}

way). Scalar invariance (loadings and intercepts of all items constrained to be equal across three regions, indicating whether the values were understood in the same way and whether the respondents used the scale in the same way) was supported only for openness to change and conservation values. However, partial scalar invariance (at least two indicator intercepts per latent variable constrained to be equal across groups) was established for the other values. It was therefore justified to compare means across regions.

\section{HIERARCHIES OF VALUES}

Table 3 presents the mean importance ratings of the seven differentiated values averaged across the representative Vietnamese sample. This is the overall hierarchy of values in Vietnam, which differs from the pan-cultural hierarchy. In Vietnam, tradition, security and conformity are the most important values, followed by benevolence and universalism. By contrast, in the pan-cultural hierarchy, tradition is $9^{\text {th }}$, security $4^{\text {th }}$ and conformity $5^{\text {th }}$ (Schwartz \& Bardi, 2001). Self-direction was located in the middle of the hierarchy, and the less important values are hedonism, achievement-power and stimulation - the same as in the pan-cultural baseline hierarchy.

There were some differences between the hierarchies of the three regions (see Figure 5). To test the 


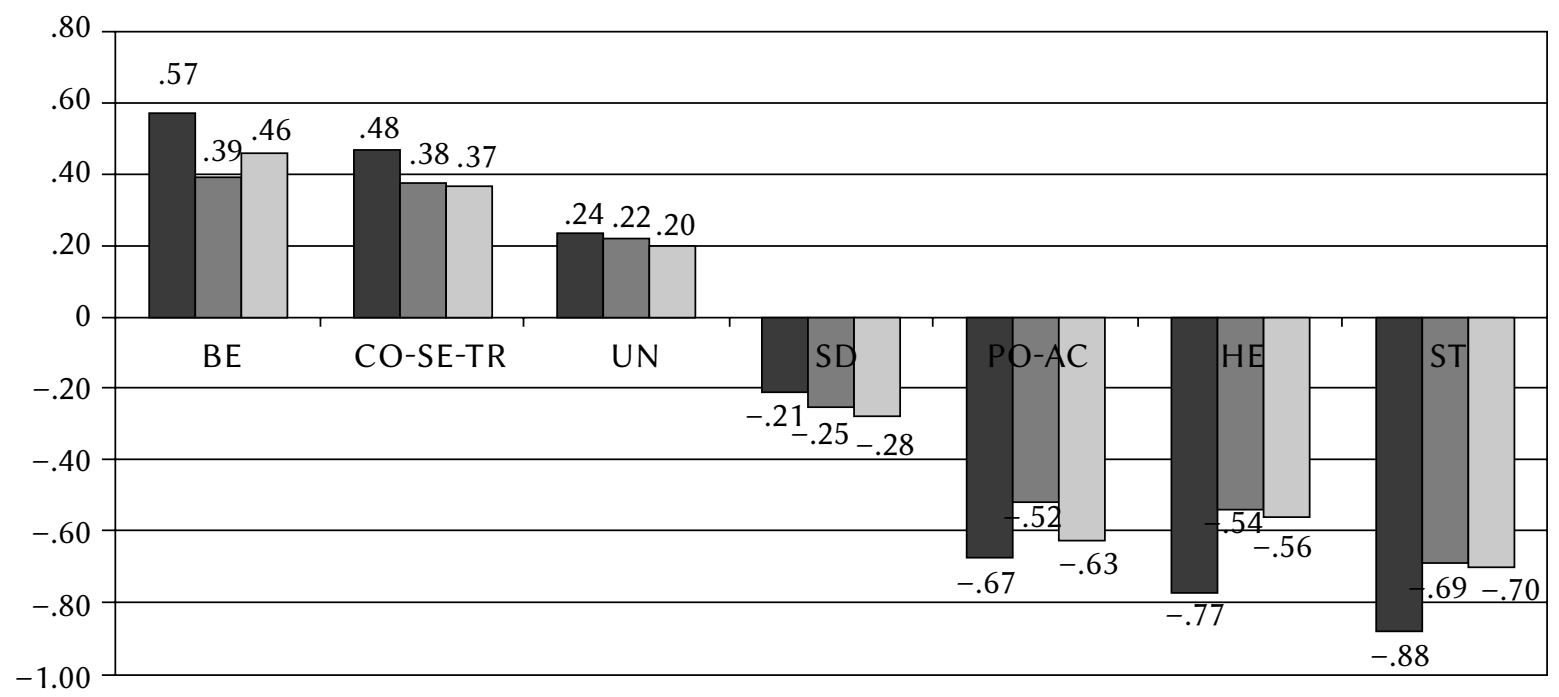

Basic human values in Vietnam

Note. CO - conformity; SE - security; TR - tradition; BE - benevolence; UN - universality; SD - self-direction; PO - power; AC - achievement; HE - hedonism; ST - stimulation; $\square$ - Hanoi; $\square$ - Saigon; $\square$ - Hue.

Figure 5. The hierarchy of values in Hanoi $(n=533)$, Hue $(n=538)$ and Saigon $(n=521)$.

significance of differences in preferences for each value between regions, we used one-way ANOVA (analysis of variance) and post hoc NIR tests. Only in Hanoi was benevolence the most preferred value; the same as the security-conformity-tradition value. In Hue, people valued self-direction significantly less. People in Saigon attributed significantly more importance to the hedonism, stimulation and powerachievement values.

\section{DISCUSSION}

\section{STRUCTURE OF VALUES IN VIETNAM}

We used MDS to verify the circular structure of relations among the values and CFA to verify the number of distinct values that can be discriminated. The analyses were executed on the PVQ-40 data collected from a large representative Vietnamese sample. The MDS analysis confirmed that it was possible to partition the value continuum into a set of basic values that form four higher order categories. The differentiated values were located around the motivational circle, as originally theorized and found repeatedly in many studies worldwide (Schwartz, 1992, 1994, 2006).

Some values needed to be unified. Both MDS and CFA showed a clear possibility for differentiating seven values. In the precise test of CFA it was necessary to unify power with achievement and tradition with conformity and security. This result does not contradict the theory, as Schwartz emphasized that the distinction of 10 values is an arbitrary decision and that the continuum can be divided into a different number of parts (see Cieciuch \& Schwartz, 2012; Schwartz et al., 2012). However, it is an interesting and substantive result that indicates the specific characteristics of Vietnamese culture.

\section{HIERARCHY OF VALUES IN VIETNAM}

Based on the value hierarchy of the Vietnamese sample, we can characterize Vietnam as a typical traditional/collectivistic country but with a complex historical, political and economic background. The results suggest that the Vietnamese are very concerned with maintaining cooperative and supportive primary relations, following tradition (security-conformitytradition, $1^{\text {st }}$ ) and helping members of their close groups (benevolence, $2^{\text {nd }}$ ) but less concerned with the welfare of strangers (universalism, $3^{\text {rd }}$ ). The Vietnamese pay less attention to gratification of self-oriented needs and desires (self-direction, $4^{\text {th }}$; hedonism, $5^{\text {th }}$ ), and to productive or innovative task performance (achievement-power, $6^{\text {th }}$; stimulation, $7^{\text {th }}$ ).

Considering these Vietnamese ratings in light of the pan-cultural hierarchy (see Schwartz \& Bardi, 2001), what stands out is the extraordinary emphasis on maintaining undisturbed social relations and following traditions. The tradition, security and conformity values are all much more important than in most countries (and more than in African samples). Accepting and acting on traditional values can contribute to group solidarity and thus to smooth group functioning and survival, promoting harmonious relations among group members (Schwartz, 1992). These values certainly served as a ground for cooperation and defense against the enemy during the war.

According to many researchers, not only history but also Vietnamese traditional agricultural culture has an impact on Vietnamese people's characteris- 
tics (Tran Ngoc Them, 1999, 2004; Tran Quoc Vuong, 2003). As stated by Tran Ngoc Them (2004), because of the dependence on nature, where just one person cannot handle all the agricultural work, the whole family, relations and neighbors always need to be together. One can assume that Vietnamese people honor obligations to clan and family for that reason. This can lead to dependence on family and lack of self-reliance. That can explain why self-direction, stimulation and self-indulgence (hedonism) values are less important than in most countries. The fact that Vietnamese respect the community more than the individual is reflected in the atypically high importance they attribute to conservation values and the low importance they attribute to openness to change values.

The hierarchies of values in the three cities of Vietnam differ somewhat, probably because of their different cultures and history. Although all Vietnamese regions attribute very great importance to security-conformity-tradition and benevolence, the preference for these values was significantly higher in Hanoi than that in Saigon or Hue. In Hue, people valued self-direction significantly less than in Hanoi and Saigon. This may reflect the fact that Hanoi and Saigon are more dynamic cities than historical Hue. People in Saigon are more economically oriented than those in Hanoi. The former are heavily involved in business and trade, possibly leading to their greater emphasis on power-achievement, stimulation and hedonism values. People in Hanoi give greater emphasis to self-transcendence and conservation values (security-conformity-tradition and benevolence), whereas people in Saigon give greater emphasis to self-enhancement and openness to change values (power-achievement, stimulation and hedonism). These differences are consistent with Ralston, Nguyen and Napier (1999), who found significant differences in values between managers from the north (influenced by Chinese culture) and the south (influenced by American culture). Specifically, the southern managers (Saigon) were more individualistic and cosmopolitan than the managers from Hanoi.

In comparison with pan-cultural hierarchy (Schwartz \& Bardi, 2001), Vietnamese prefer much more conservative values (security-conformity-tradition $1^{\text {st }}$ ) than openness to change (self-direction $4^{\text {th }}$, hedonism $5^{\text {th }}$ ) and self-enhancement values (power-achievement, ranked last). This is unlike most other nations, which attribute more importance to openness to change values (self-direction $2^{\text {nd }}$ ) than to conservation values (security $4^{\text {th }}$, conformity $5^{\text {th }}$, tradition $9^{\text {th }}$ ). It is worth noting that the value preferences in Saigon, the most Westernized city, are most similar to the pan-cultural world baseline hierarchy.

To conclude, our study shows that the pan-cultural structure, assumed in the circular model of values, and the pan-cultural hierarchy of values, found in many empirical studies around the world conduct- ed in this model, can serve as a reference frame for studying both the value structure and hierarchy in a specific culture. The structure of values in Vietnam corresponded to the patterns of similarity and opposition among the values in the theory, although not all the values could be differentiated. Some values had to be unified (e.g. security-conformity-tradition), but the values that were unified were always those adjacent in the motivational circle of the theory. Regarding the hierarchy of values, the differences between the hierarchy in Vietnam and the pan-cultural hierarchy reflected the more traditional/collectivist culture of the country. Moreover, the differences between the cities reflected the degree of their exposure to the West, their political histories, and the nature of their economies. The strengths of this study are revealing both universal aspects of values in Vietnam (e.g., the circular structure of value relations) and culturally specific aspects (e.g., the unique hierarchy of values in the country and in three different cities). The limitations of this research are lack of testing any external variables and lack of comparison with other countries. In future research, it would be worthwhile to explore correlates and consequences of the values in Vietnam, in comparison with different cultures.

The work of Truong Thi Khanh Ha was supported by Vietnam National University, Hanoi (VNU) under project number QG.17.04. The work of Jan Cieciuch was supported by Grant 2011/01/D/HS6/04077 from the National Science Centre, Poland. We would like to thank Nguyen Van Luot, Tran Ha Thu, Dau Minh Long and Nguyen Dinh Phong for gathering the data. The work of the fourth author on this paper was partly supported by the HSE Basic Research Program (International Laboratory of Sociocultural Research).

\section{REFERENCES}

Berry, J. W. (2004). An ecocultural perspective on the development of competence. In R. J. Sternberg \& E. L. Grigorenko (eds.), Culture and competence. Context of life success (pp. 3-22). Washington: APA.

Bilsky, W., Janik, M., \& Schwartz, S. H. (2011). The structural organization of human values: Evidence from three rounds of the European Social Survey (ESS). Journal of Cross-Cultural Psychology, 42, 759-776. doi: 10.1177/0022022110362757

Bollen, K. A. (1989). Structural equations with latent variables. New York, NY: Wiley.

Bond, M. H., Leung, K., Au, A., Tong, K. K., De Carrasquel, S. R., Murakami, F., Yamaguchi, S., Bierbrauer, G., Singelis, T. M., Broer, M., Boen, F., Lambert, S. M., Ferreira, M. C., Noels, K. A., Van Bavel, J., Safdar, S., Zhang, J., Chen, L., Solcova, I., \& Stetovska, I. (2004). Culture level dimensions of social axioms and their correlates across 41 
cultures. Journal of Cross-Culture Psychology, 35, 548-570. doi: 10.1177/0022022104268388

Brown, T. A. (2006). Confirmatory factor analysis for applied research. New York, NY: Guilford Press.

Browne, M. W., \& Cudeck, R. (1993). Alternative ways of assessing model fit. In K. A. Bollen \& J. S. Long (eds.), Testing structural equation models (pp. 136-162). Newbury Park, CA: SAGE.

Chen, F. (2007). Sensitivity of goodness of fit indexes to lack of measurement invariance. Structural Equation Modeling, 14, 464-504. doi: 10.1080/10705510701301834

Cieciuch, J., \& Schwartz, S. H. (2012). The number of distinct basic values and their structure assessed by PVQ-40. Journal of Personality Assessment, 94, 321-328. doi: 10.1080/00223891.2012.655817

Dao Duy Anh. (2000). Viet Nam van hoa su cuong [General history of Vietnamese culture]. Hanoi: The Vietnam Writers' Association Publishing House.

Davidov, E., Meuleman, B., Cieciuch, J., Schmidt, P., \& Billiet, J. (2014). Measurement equivalence in cross-national research. Annual Review of Sociology, 40, 55-75. doi: 10.1146/annurev-soc071913-043137

Hitlin, S., \& Piliavin, J. A. (2004). Values: Reviving a dormant concept. Annual Review of Sociology, 30, 359-393.

Hofstede, G. (1991). Cultures and organizations: Software of the mind. London: McGraw-Hill.

House, R. J., Hanges, P. J., Javidan, M., Dorfman, P. W., \& Gupta, V. (2004). Culture, leadership, and organizations. The GLOBE study of 62 societies. Thousand Oaks: Sage.

Hu, L., \& Bentler, P. M. (1999). Cutoff criteria for fit indexes in covariance structure analysis: Conventional criteria versus new alternatives. Structural Equation Modeling, 6, 1-55. doi: 10.1080/10705519909540118

Inglehart, R. (1997). Modernization and postmodernization: Cultural, economic and political change in 43 societies. Princeton, NJ: Princeton University Press.

Jöreskog, K. (1971). Simultaneous factor analysis in several populations. Psychometrika, 36, 409-426. doi: 10.1007/BF02291366

Koivula, N., \& Verkasalo, M. (2006). Value structure among students and steelworkers. Journal of Applied Social Psychology, 36, 1263-1273. doi: 10.1111/j.0021-9029.2006.00041

Liem, G. A. D., Martin A. J., Nair, E., Bernardo, A. B. I., \& Hidajat, P. P. (2011). Content and Structure of Values in Middle Adolescence: Evidence From Singapore, the Philippines, Indonesia, and Australia. Journal of Cross-Cultural Psychology, 42, 146-154. doi: 10.1177/0022022110383309

Markus, H. R., \& Kitayama, S. (1991). Culture and the self: Implications for cognition, emotion and motivation. Psychological Review, 98, 224-253.
Muthén, L., \& Muthén, B. O. (1998-2012). Mplus user's guide (Version 7). Los Angeles, CA: Author.

Le Thi Lan. (2009). The Vietnamese tradition of reconciling cultures and religions. In D. G. Adian \& G. Arivia (eds.), Prospects, Relations between Religious and cultures in Southeast Asia: Indonesian Philosophical Studies (pp. 215-222). Washington D.C.: The Council for Research in Values and Philosophy.

Pham Minh Hac. (1998). Dialectics of national values and world values - the case of Vietnam. In Tran Ngoc Them (ed.), Research on the Identity of Vietnamese Culture (pp. 1-6), Hanoi: World Publisher.

Ralston, D. A., Nguyen, V. T., \& Napier, N. K. (1999). A comparative study of the work values of North and South Vietnamese managers. Journal of International Business Studies, 30, 655-672. doi: 10.1057/palgrave. jibs.8490889

Rohan, M. J. (2000). A rose by any name? The values construct. Personality and Social Psychology Review, 4(3), 255-277. doi: 10.1207/S15327957PSPR0403_4

Rokeach, M. (1973). The nature of human values. New York, NY: Free Press.

Różycka-Tran, J., Żemojtel-Piotrowska, M., \& Truong, T. K. H. (2013). Wartości osobiste i kulturowe w ujęciu Shaloma Schwartza, w kulturze polskiej i wietnamskiej [Schwartz'personal and cultural values in Polish and Vietnamese cultures]. Psychologia Spoteczna, 4, 396-407.

Sagiv, L., \& Schwartz, S. H. (2007) Cultural values in organisations: insights for Europe. European Journal of International Management, 1, 176-190. doi: 10.1504/EJIM.2007.014692

Schmidt, P., Bamberg, S., Davidov, E., Herrmann, J., \& Schwartz, S. H. (2007). Die Messung von Werten mit dem "Portraits Value Questionnaire" [Measurement of values with the "Portrait Values Questionnaire"]. Zeitschrift fur Sozial Psychologie, 38, 249-263.

Schwartz, S. H. (1992). Universals in the content and structure of values: Theory and empirical tests in 20 countries. In M. Zanna (ed.), Advances in experimental social psychology (vol. 25) (pp. 1-65). New York, NY: Academic Press.

Schwartz, S. H. (1994). Are there universal aspects in the content and structure of values? Journal of Social Issues, 50, 19-45. doi: 10.1111/j.15404560.1994.tb01196

Schwartz, S. H. (2004). Mapping and interpreting cultural differences around the world. In H. Vinken, J. Soeters, \& P. Estes (eds.), Comparing cultures. Dimensions of culture in a comparative perspective (pp. 43-73). The Netherlands: Brill.

Schwartz, S. H. (2005). Robustness and fruitfulness of the theory of universals in individual human values. In A. Tamayo \& J. Porto (eds.), Values and behavior in organizations (pp. 56-95). Brasilia: Editora Universidade de Brasilia.
Basic human values in Vietnam 
Schwartz, S. H. (2006). A theory of cultural value orientations: explication and applications. Comparative Sociology, 5, 137-182. doi: 10.1163/ 156913306778667357

Schwartz, S. H., \& Bardi, A. (2001). Value hierarchies across cultures: Taking a similarities perspective. Journal of Cross-Cultural Psychology, 32, 268-290. doi: 10.1177/0022022101032003002

Schwartz, S. H., \& Bilsky, W. (1987). Toward a universal psychological structure of human values.

Joanna

Różycka-Tran, Truong Thi Khanh $\mathrm{Ha}$, Jan Cieciuch, Shalom H. Schwartz Journal of Personality and Social Psychology, 53, 550-562. doi: 10.1037/0022-3514.53.3.550

Schwartz, S. H., Cieciuch, J., Vecchione, M., Davidov, E., Fischer, R., Beierlein, C., \& Konty, M. (2012). Refining the theory of basic individual values. Journal of Personality and Social Psychology, 103, 663-688. doi: 10.1037/a0029393

Schwartz, S. H., Melech, G., Lehmann, A., Burgess, S., \& Harris, M. (2001). Extending the cross-cultural validity of the theory of basic human values with a different method of measurement. Journal of Cross-Cultural Psychology, 32, 519-542. doi: 10.1177/0022022101032005001

Tran Dinh Huou. (1994). About finding out national cultural identity. To modernity from tradition. Hanoi: The Culture Publishing House.

Tran Ngoc Them. (1999). Establishments of Vietnamese culture. Hanoi: Education Published House.

Tran Ngoc Them. (2004). Research on the Identity of Vietnamese Culture. Hanoi: World Publisher.

Tran Ngoc Them. (2015). Some issues about Vietnamese value system in the present-time. Ho Chi Minh City: Vietnam National University Publishing House.

Tran Quoc Vuong. (2003). The Vietnamese culture. Searching and thinking. Hanoi: Literature Published House.

Tran Van Giau. (1980). Spiritual traditions of Vietnam nation. Hanoi: Social Sciences Publisher.

Truong, T. K. H., Nguyen, V. L. \& Różycka-Tran, J. (2015). Similarities and differences in values between Vietnamese parents and adolescents. Health Psychology Report, 3(4), 281-291. doi: 10.5114/hpr.2015.51933

Vecchione, M., Casconi, T., \& Barbaranelli, C. (2009). Assessing the circular structure of the Portrait Values Questionnaire. European Journal of Psychological Assessment, 25, 231-238. doi: 10.1027/10155759.25.4.231

World Values Survey (WVS). Wave 4 1999-2004 OFFICIAL AGGREGATE v.20140429. World Values Survey Association (www.worldvaluessurvey.org). Madrid SPAIN: Aggregate File Producer: sep/JDS. 